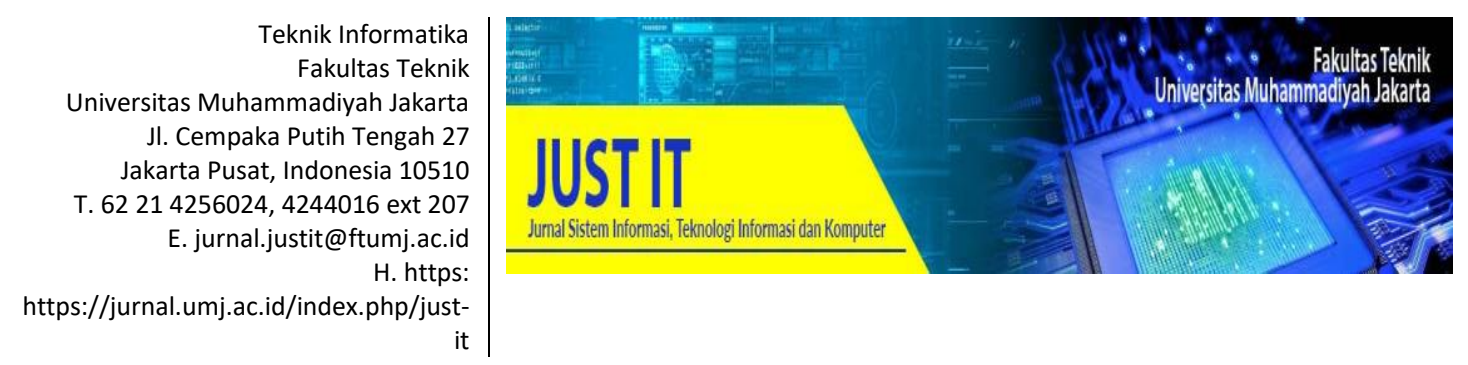

\title{
PERANCANGAN APLIKASI PENYEWAAN ALAT HIKIING DI TOKO GREEN CAMPUS DAERAH CILANDAK BERBASIS JAVA NETBEANS
}

\author{
Kiki Dwi Laksmana ${ }^{1}$, Yoggi Prasetyo Octavian², Caka Gatot Priambodo ${ }^{3}$ \\ Program Studi Informatika, Universitas Indraprasta PGRI, Jakarta - Indonesia \\ kikidwilaksmana10@gmail.com,yoggip.octavian@gmail.com, cakagatot15@gmail.com,
}

\begin{abstract}
Abstrak
Komputer diciptakan untuk membantu manusia dalam pemecahan dan penyelesaian masalah. Para pengusaha besar maupun kecil yang mencoba untuk memanfaatkan kecanggihan dan perkembangan teknologi khususnya penyewaan alat hiking sehingga membuat penulis merancang aplikasi penyewaan alat hiking. Tujuan Penelitian adalah Tujuan dari penelitian ini adalah untuk merancang sebuah aplikasi Penyewaan Alat Hiking Di Toko Green Campus agar pengelolaan data barang, dan pengolahan data lain pada toko green campus lebih akurat dan terstruktur, Membuat sebuah aplikasi penyewaan yang efektif dan efisien sesuai dengan kebutuhan di toko green campus, Membuat aplikasi penyewaan yang user friendly, Untuk mengimplementasikan perancangan aplikasi Penyewaan Alat Hiking Di Toko Green Campus, Untuk membuat perancangan aplikasi penyewaan alat hiking di toko green campus.

Kata Kunci : Perancangan, Aplikasi, Penyewaan, Alat Hiking, Toko Green Campus.
\end{abstract}

\begin{abstract}
Computer created to help a man in the solution and problem resolution .The large companies or small who tries to use sophistication and technology development especially rental instrument hiking so as to make writer design application rental instrument hiking .Research objectives is the aim of this research is to design an application rental instrument hiking in a shop green campus ensure that the management of data goods, and processing other data in a shop green campus more accurate and structured, making an application rental an effective and efficient in accordance with the needs store green campus, make application rental who user friendly, to implement design application rental instrument hiking in a shop green campus, to make design application rental instrument hiking in a shop green campus.

Keywords: Design, Application, Rental, Instrument Hiking , Shop Green Campus.
\end{abstract}

\section{PENDAHULUAN}

Pada zaman era globalisasi yang terjadi saat ini sangat mempengaruhi kehidupan setiap individu, maupun perusahaan dari segi teknologi, dan kehidupan manusia menjadi lebih mudah, efektif, dan hemat. Hal ini disebab kan karena keterbatasan manusia dalam hal kecepatan dan ketelitian. Penggunaan komputer saat ini telah menjadi suatu kebutuhan yang sangat penting, hal ini didukung dengan semakin banyaknya para pegembang teknologi informasi yang dituntut 
untuk lebih kreatif dan inovatif dalam memajukan industri komputer.

Komputer merupakan salah satu perangkat yang didalamnya terdapat perangkat keras (hardware) dan perangkat lunak (software) yang direncang atau dibuat dengan menggunakan berbagai bahasa pemograman. Komputer diciptakan untuk membantu manusia dalam pemecahan dan penyelesaian masalah.

Menurut Bambang Hartono (2013:10) "Sehimpunan bagian-bagian atau komponen yang saling berkaitan dan secara bersama-sama berfungsi atau bergerak untuk mencapai suatu tujuan." (Hartono, 2013). Menurut Rosa dan Shalahuddin, "ERD adalah pemodelan awal basis data yang dikembangkan berdasarkan teori himpunan dalam bidang matematika. ERD digunakan untuk pemodelan basis data relasional." (Sukamto \& Shalahudin, 2013). Menurut Indrajani (2011:33) "basis data merupakan suatu kumpulan data yang berhubungan secara logis dan deskripsi data tersebut, yang dirancang untuk memenuhi informasi yang dibutuhkan oleh suatu organisasi. Artinya, basis data merupakan tempat penyimpan data yang besar dimana dapat digunakan oleh banyak pengguna." (Indrajani, 2011). Menurut Syamsu Rizal (2013:25), "aplikasi adalah penggunaan dalam suatu perangkat komputer, instruksi (instruction) atau pernyataan (statement) yang disusun hingga sedemikian rupa komputer dapat memproses masukan (input) menjadi keluaran (output)." (Tjiptjono, 2011). Menurut Fathansyah (2012:39) "Dalam proses normalisasi, persyaratan sebuah table masih harus di pecah didasarkan adanya kesulitan kondisi pengorganisasian data seperti untuk m enambah atau menyisipkan, menghapus atau mengubah, serta pembacaan data dari tabel tersebut. Bila masih ada kesulitan, maka tabel harus dipecah menjadi beberapa lagi, dan dilakukan proses normalisasi kembali sampai diperoleh tabel yang optimal." (Fathansyah, 2012).

\section{METODE PENELITIAN}

Tempat dan Waktu Penelitian

Penelitian ini dilakuka pada bagian pendataan barang di Toko Green Campus untuk melakukan perancangan aplikasi penyewaan alat hiking yang akan penulis buat, Alat Hiking Jakarta Selatan beralamat Jl. Cilandak KKO RT 005/RW 05 No. 61 kel. Ragunan, kec. Pasar Minggu, Jakarta Selatan, 12560 telpon : 082215598608.

Tabel 2.1 Jadwal Kegiatan

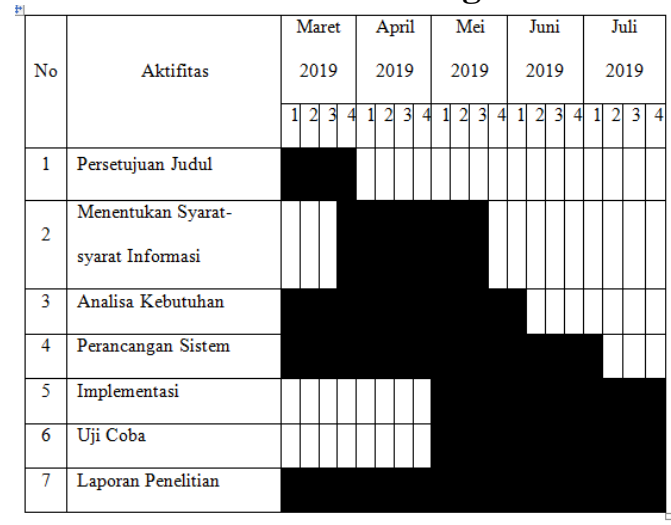

\section{Metode Penelitian}

Penelitian Pendidikan dan pengembangan ( $R$ \& D) adalah proses yang digunakan untuk mengembangkan dan memvalidasi produk pendidikan.

Sebagai suatu pola, cara penelitian tidak bersifat kaku bagaimanapun suatu cara hanyalah alat untuk mencapai suatu tujuan.

\section{Metode Pengumpulan Data}

Dalam penelitian ini peluis melakukan pengumpulan data yang digunakan digunakan dalam dua (2) metode yaitu :

1. Study Kepustakaan

Penulis mengumpulkan data-data dari rujukan buku-buku, internet serta sumber ilmiah lain yang berkaitan dengan penelitian. Dalam hal ini penulis malakukan studi pustaka yang dapat menunjang penulisan tugas akhir.

2. Studi Lapangan

Data yang dihimpun secara langsung dari sumbernya dan diolah sendiri untuk dimanfaatkan. Data primer data berbentuk opini subjek secara individu atau kelompok, dan hasil observasi terdapat kejadian, kegiatan dan hasil suatu pengujian tertentu. Pada penelitian ini penulis mengambil data dari yaitu :

a. Wawancara

Wawancara dilakukan kepada pemilik Toko Green Campus Cilandak. Penulis mengadakan tanya 
jawab kepada pemilik toko mengenai sistem pengolahan data toko di cilandak untuk memperoleh data yang jelas dan akurat guna melengkapi penyusunan penulisan tugas akhir ini.

b. Pengamatan Langsung (Observasi) Pengamatan langsung atau observasi adalah pengumpulan data dan informasi. Penulis mengumpulkan setiap data dan informasi dalam kegiatan sewa menyewa alat hiking yang berjalan di Toko Green Campus.

\section{Langkah-langkah Pengembangan Sistem}

Metodologi pengembangan sistem yang digunakan adalah metode Waterfall. Dengan tahapan seperti pada gambar berikut :

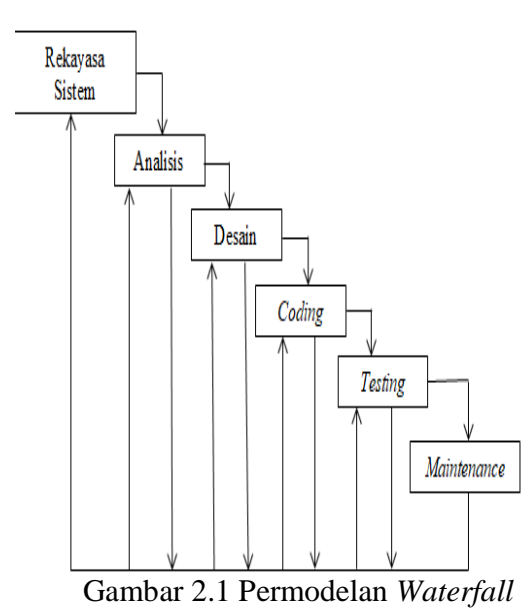

\section{HASIL DAN PEMBAHASAN}

Penulis membuat aplikasi penyewaan ini untuk pendataan di toko green campus tersebut. Selain itu penulis juga memberikan beberapa fitur, yaitu akses login, data barang, data supplier, data karyawan, data pelanggan, data pemesanan ke supplier, data pembelian barang supplier, data penyewaan, dan laporan dari setiap data. Berikut ini merupakan penggambaran tentang sistem yang diusulkan pada aplikasi penyewaan di toko green campus secara keseluruhan dalam bentuk diagram konteks.

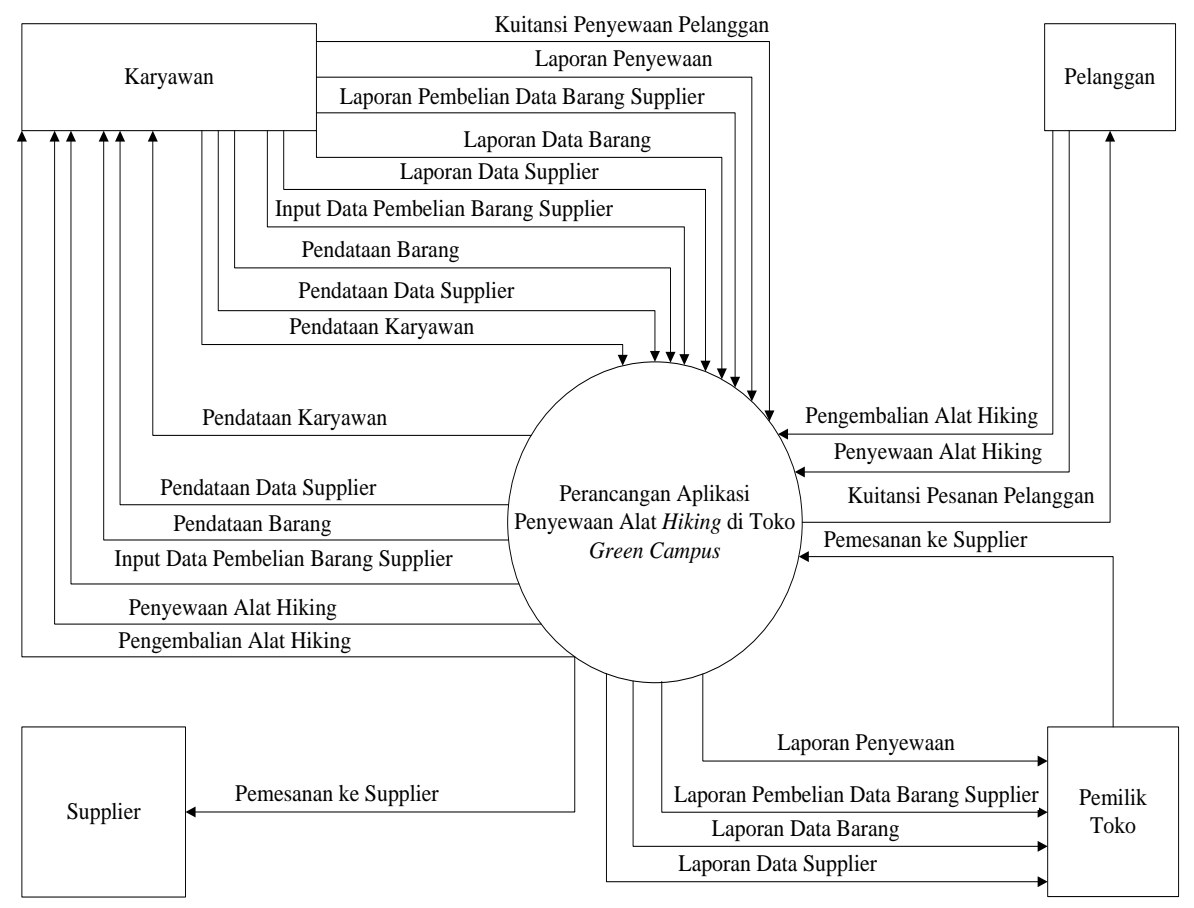

Gambar 3.1 Diagram konteks sistem diusulkan 

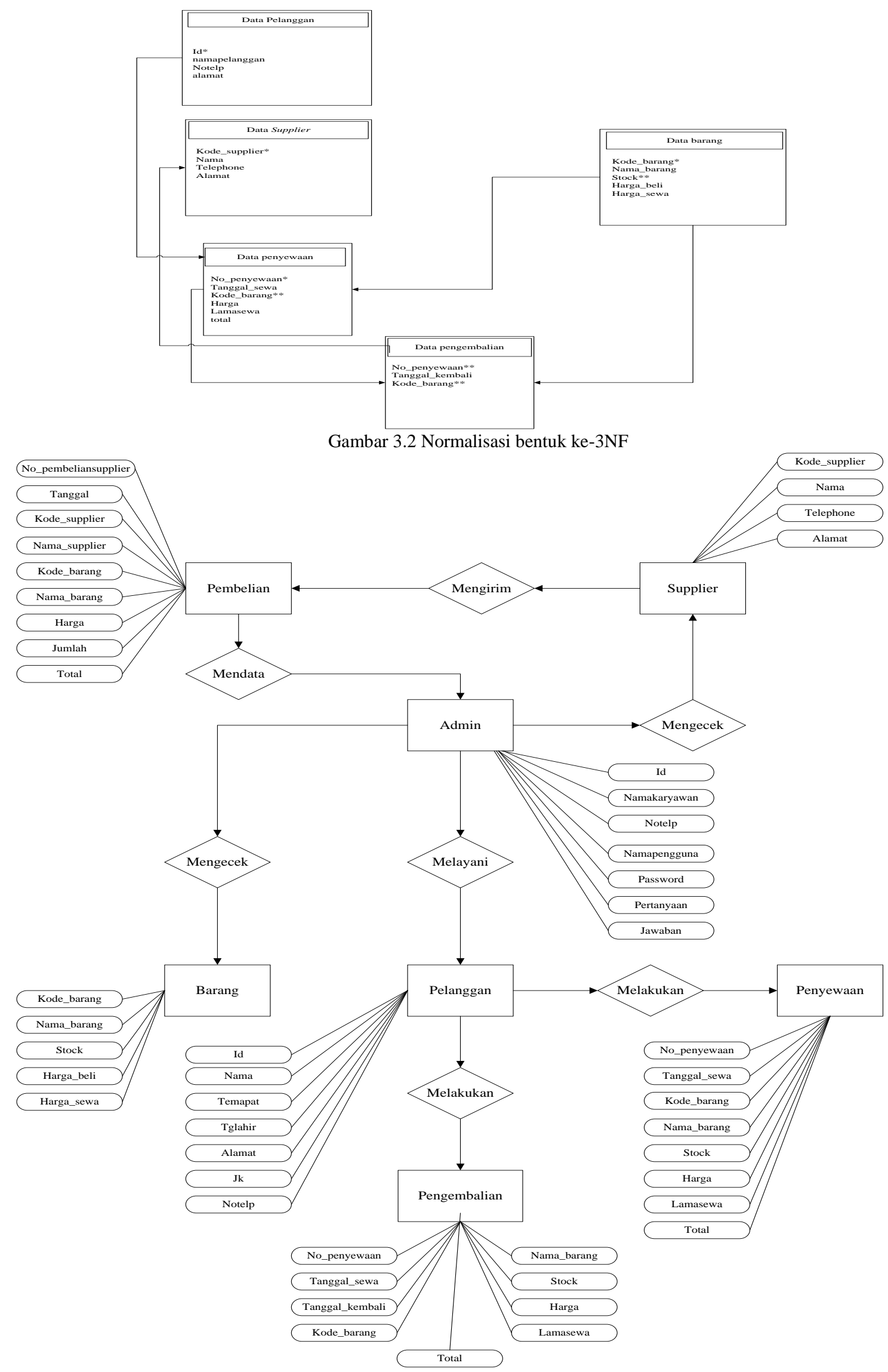

Gambar 3.3 Diagram ERD (Entity Relationship Diagram 


\section{Tampilan Layar}

Tampilan Login

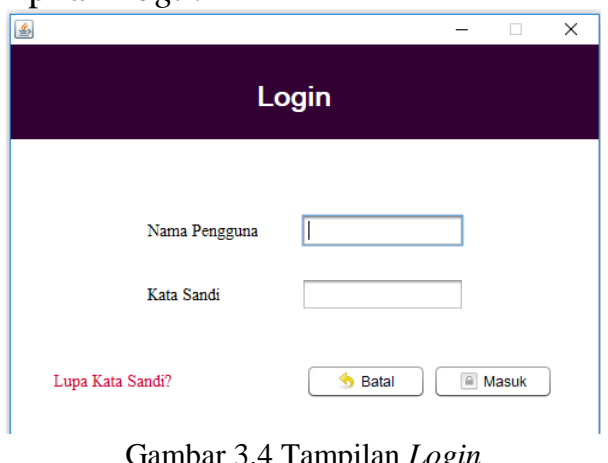

Gambar 3.4 Tampilan Login

Masukan nama dan kata sandi yang sesuai dengan hak akses, untuk dapat masuk ketampilan Menu Utama.

Tampilan Lupa Password

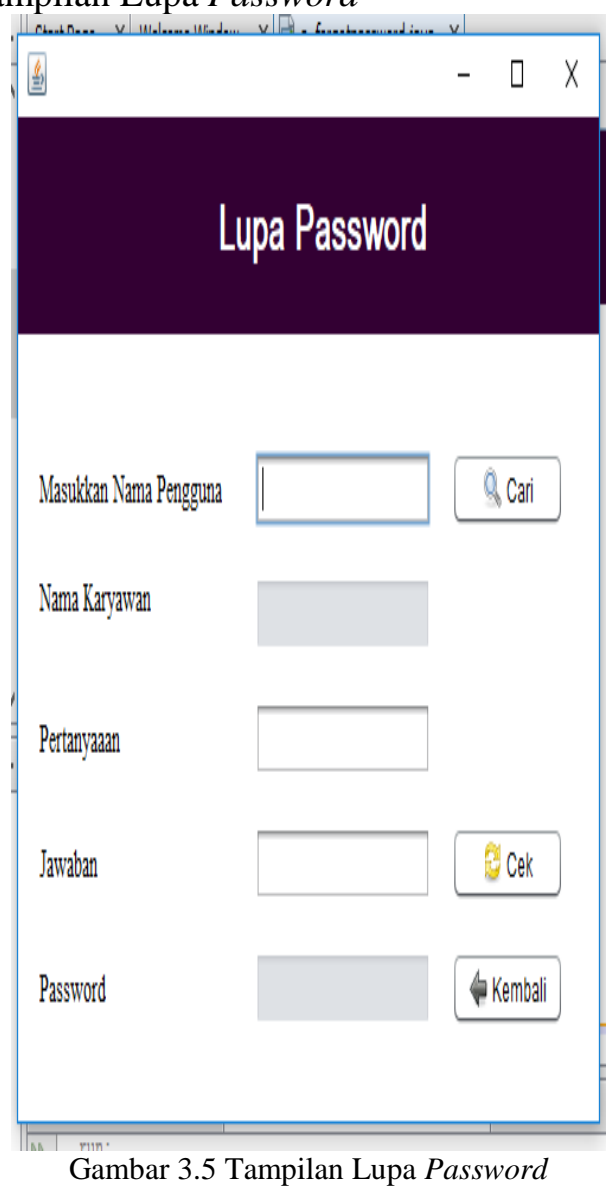

Tampilan lupa password untuk membantu user tidak bisa login atau lupa password.
Tampilan Menu Utama

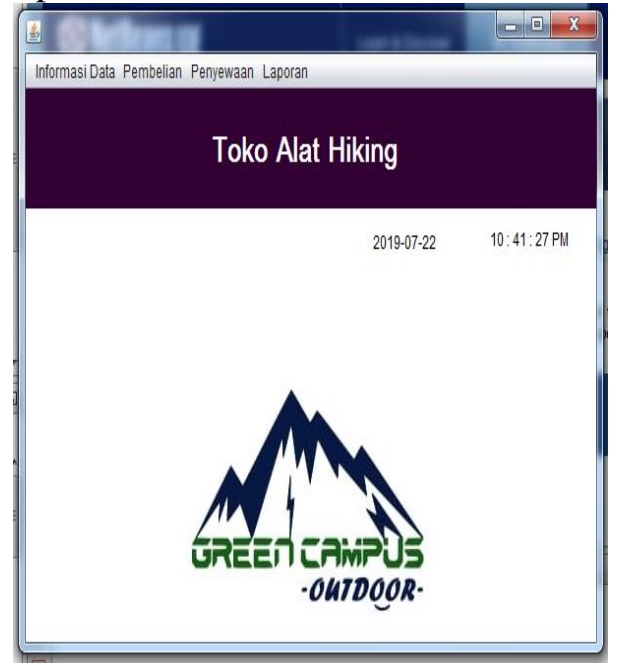

Gambar 3.6 Tampilan Menu Utama

Tampilan menu utama in terdapat beberapa icon diantaranya adalah : menu informasi data, menu pembelian, dan menu laporan.

Tampilan Form Masukan Data Tampilan Form Data Barang

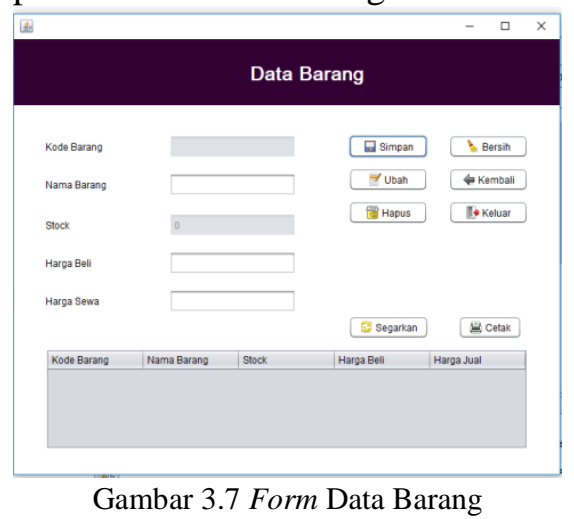

Tampilan form data barang ini, user dapat melakukan penamahan data barang (simpan), mengubah (ubah), dan menghapus data barang (hapus). Pilih tombol (x) apabila ingin menutup form data barang.

Tampilan Form Data Supplier

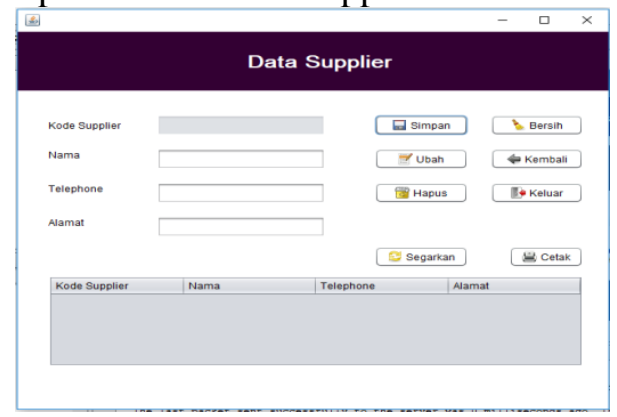

Gambar 3.8 Tampilan Form Data Supplier 
Tampilan form data supplier ini, user dapat melakukan penamahan data supplier (simpan), mengubah (ubah), dan menghapus data supplier (hapus). Pilih tombol (x) apabila ingin menutup form data supplier.

\section{Tampilan Form Data Pelanggan}

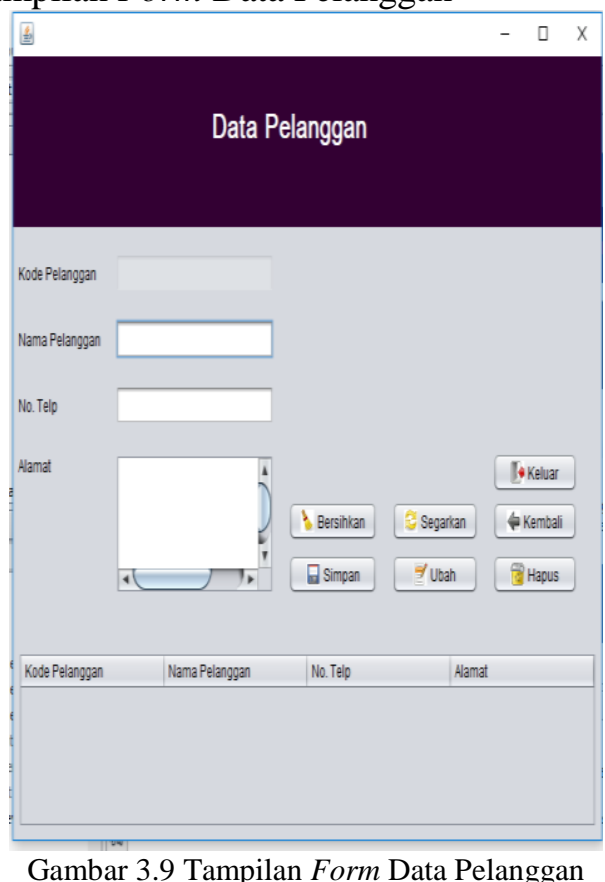

Tampilan form data pelanggan ini, user dapat melakukan penamahan data pelanggan (simpan), mengubah (ubah), dan menghapus data pelanggan (hapus). Pilih tombol (x) apabila ingin menutup form data pelanggan.

Tampilan Form Data Karyawan

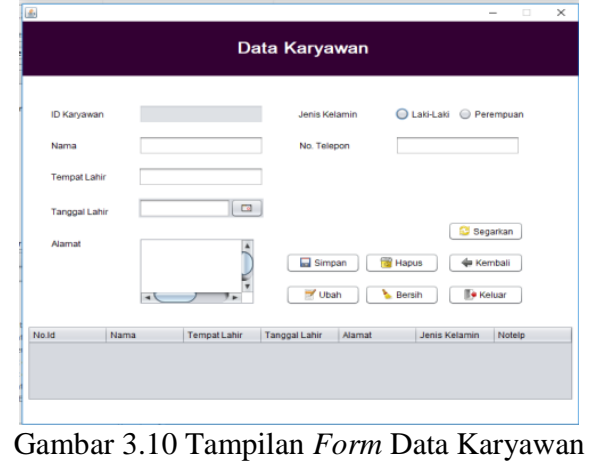

Tampilan form data karyawan ini, user dapat melakukan penamahan data karyawan (simpan), mengubah (ubah), dan menghapus data karyawan (hapus). Pilih tombol (x) apabila ingin menutup form data karyawan.
Tampilan Form Data User

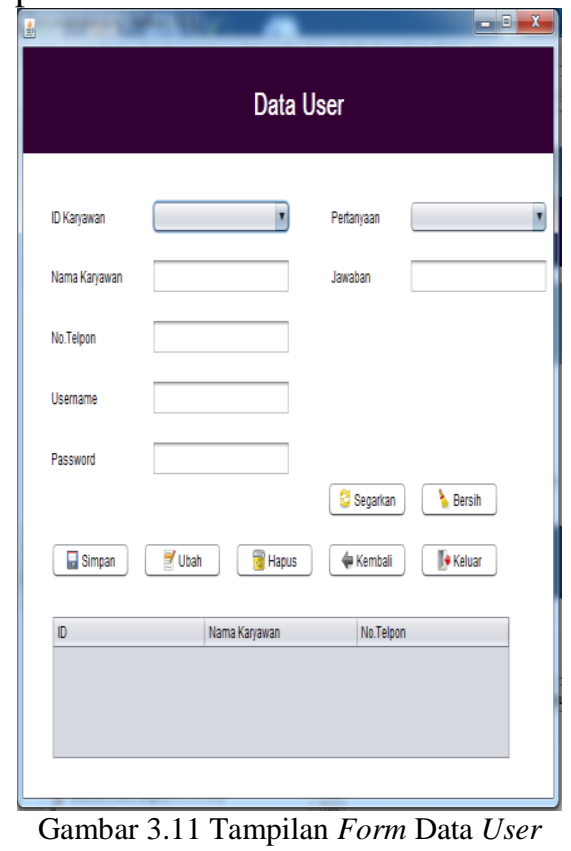

Tampilan form data user ini, user dapat melakukan penamahan data user (simpan), mengubah (ubah), dan menghapus data user (hapus). Pilih tombol (x) apabila ingin menutup form data user.

Tampilan Form Data Pemesana ke Supplier

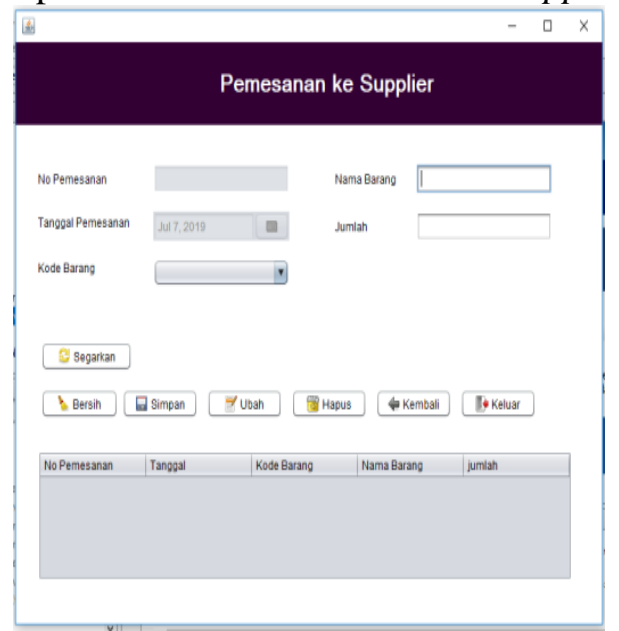

Gambar 3.12 Tampilan Form Pemesanan ke Supplier

Tampilan form data pemesanan ke supplier ini, user dapat melakukan penamahan data pemesanan ke supplier (simpan), mengubah (ubah), dan menghapus data pemesanan ke supplier (hapus). Pilih tombol (x) apabila ingin menutup form data pemesanan ke supplier. 
Tampilan Form Data Pembelian Barang Supplier

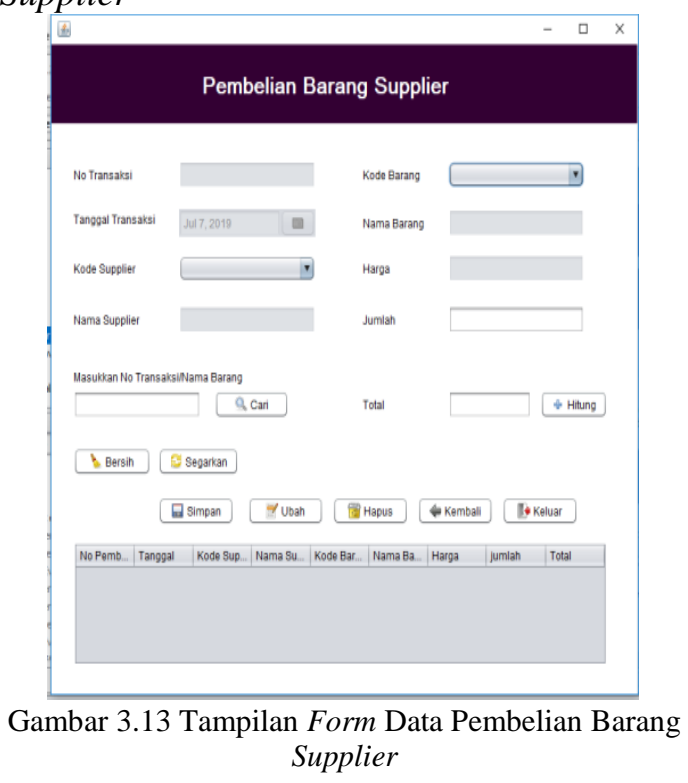

Tampilan form data pembelian barang supplier, user dapat melakukan penamahan data pembelian barang supplier (simpan), mengubah (ubah), dan menghapus data pembelian barang supplier (hapus). Pilih tombol (x) apabila ingin menutup form data pembelian barang supplier.

Tampilan Form Data Penyewaan

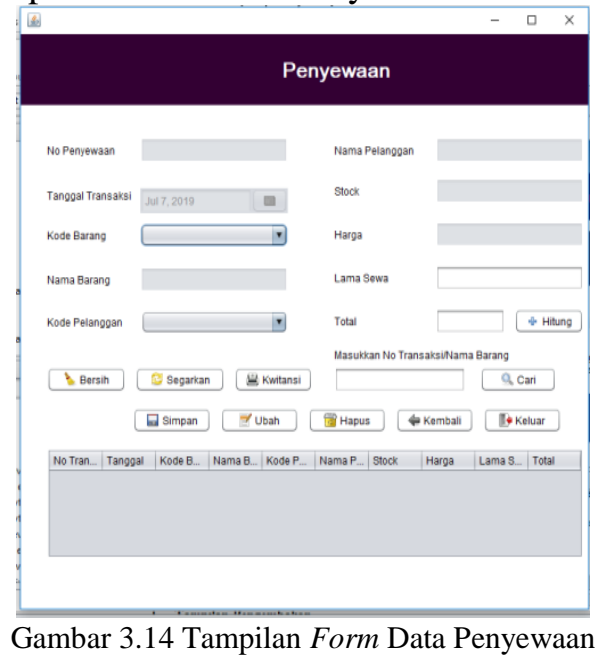

Tampilan form data penyewaan ini, user dapat melakukan penamahan data penyewaan (simpan), mengubah (ubah), dan menghapus data penyewaan (hapus). Pilih tombol (x) apabila ingin menutup form data penyewaan.
1. Tampilan Form Data Pengembalian

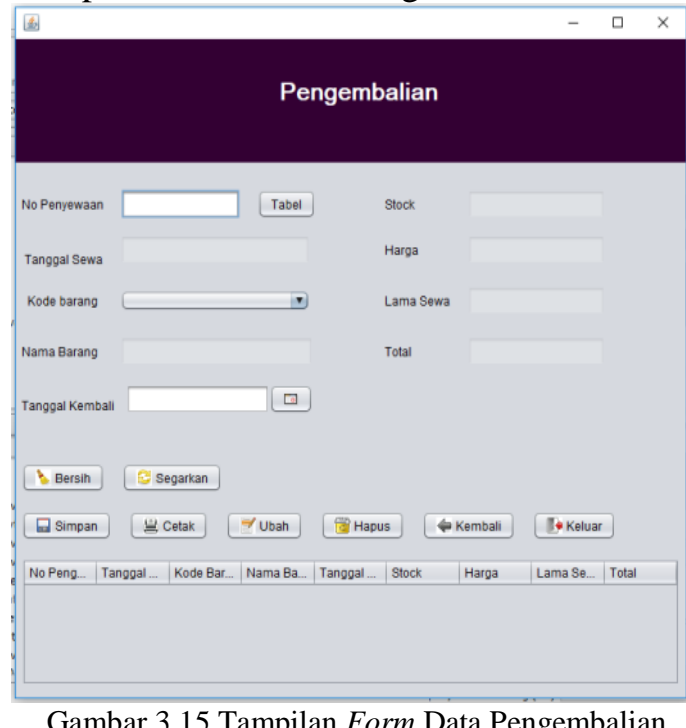

Tampilan form data pengembalian ini, user dapat melakukan penamahan data pengembalian (simpan), mengubah (ubah), dan menghapus data pengembalian (hapus). Pilih tombol (x) apabila ingin menutup form data pengembalian.

\section{Tampilan Form Keluaran}

Tampilan Keluaran Data Barang

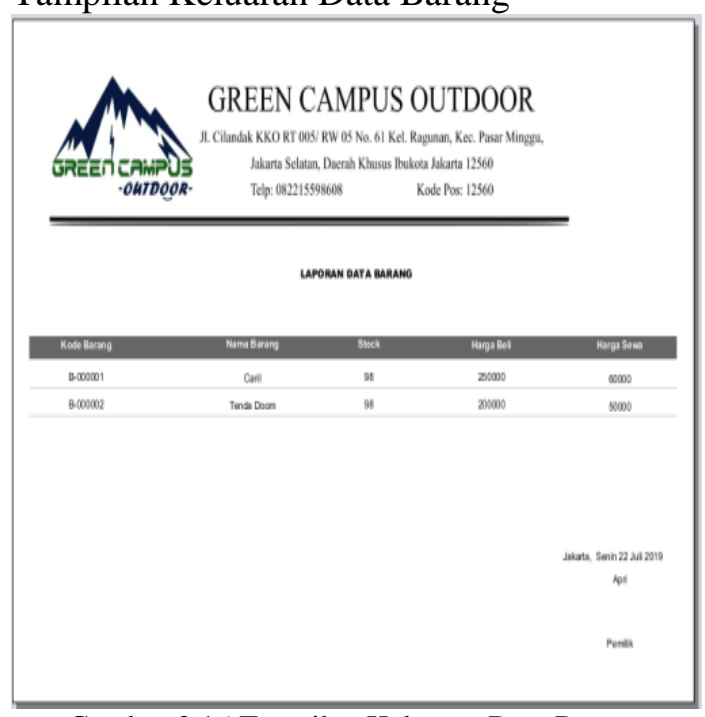

Gambar 3.16 Tampilan Keluaran Data Barang

Tampilan laporan data barang ini berisi data-data yang ada pada tabel data barang. Laporan ini muncul ketika user mengklik tombol cetak pada form laporan data barang. 
Tampilan Data Supplier

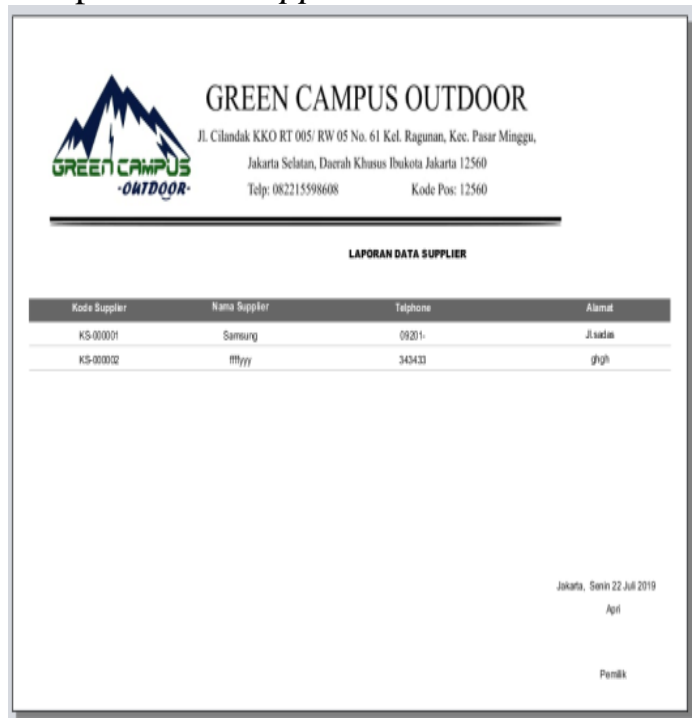

Gambar 3.17 Tampilan Data Supplier

Tampilan laporan Data Supplier ini berisi data-data yang ada pada tabel Data Supplier. Laporan ini muncul ketika user mengklik tombol cetak pada form laporan data supplier.

Tampilan Keluaran Data Penyewaan

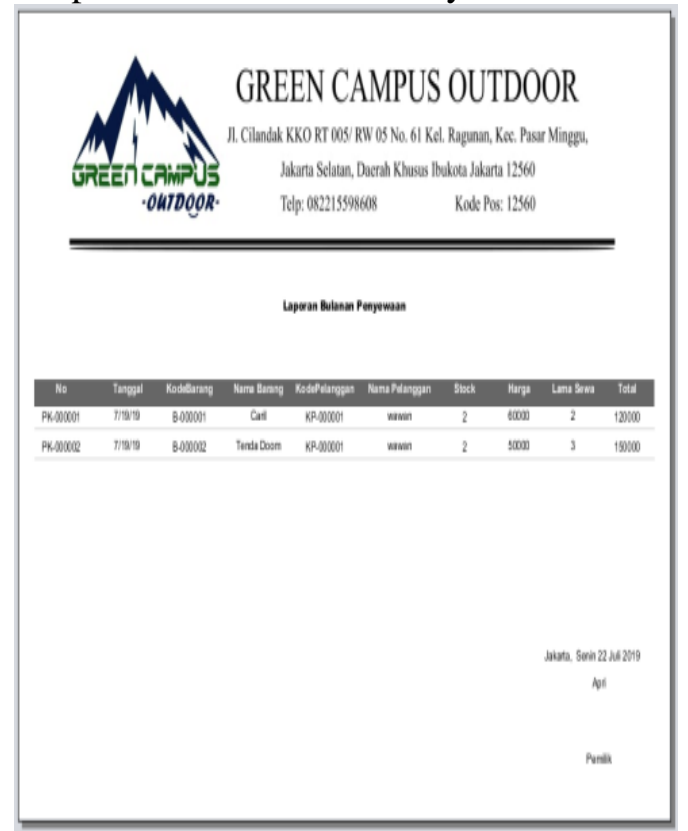

Gambar 3.18 Tampilan Keluaran Data Penyewaan

Tampilan laporan data penyewaan ini berisi data-data yang ada pada tabel data penyewaan. Laporan ini muncul ketika user mengklik tombol cetak pada form laporan data penyewaan.
Tampilan Keluaran Pembelian Barang Supplier

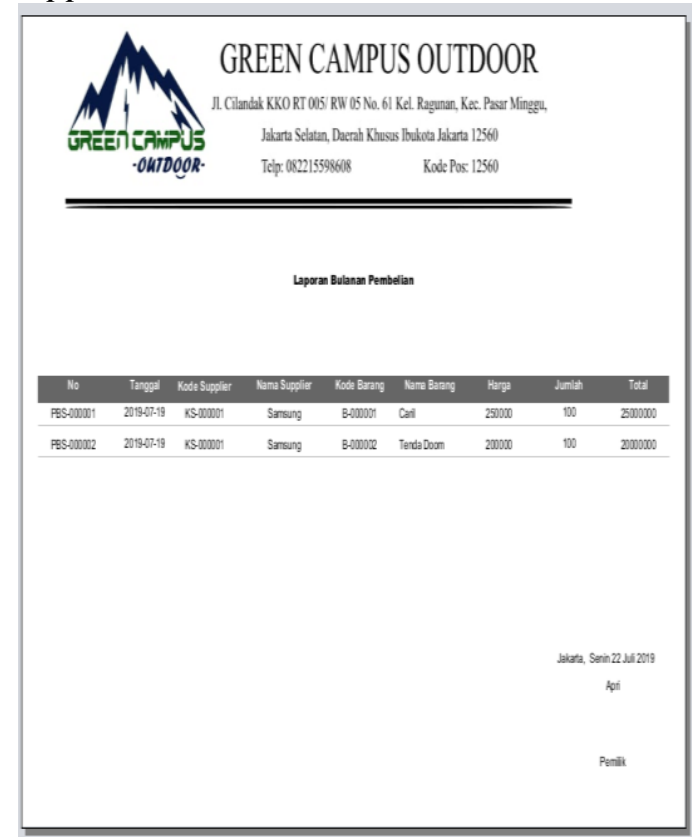

Gambar 3.19 Tampilan Keluaran Pembelian Barang Supplier

Tampilan laporan data pembelian barang supplier ini berisi data-data yang ada pada tabel data pembelian barang supplier. Laporan ini muncul ketika user mengklik tombol cetak pada form laporan data pembelian barang supplier.

Tampilan Keluaran Kwitansi

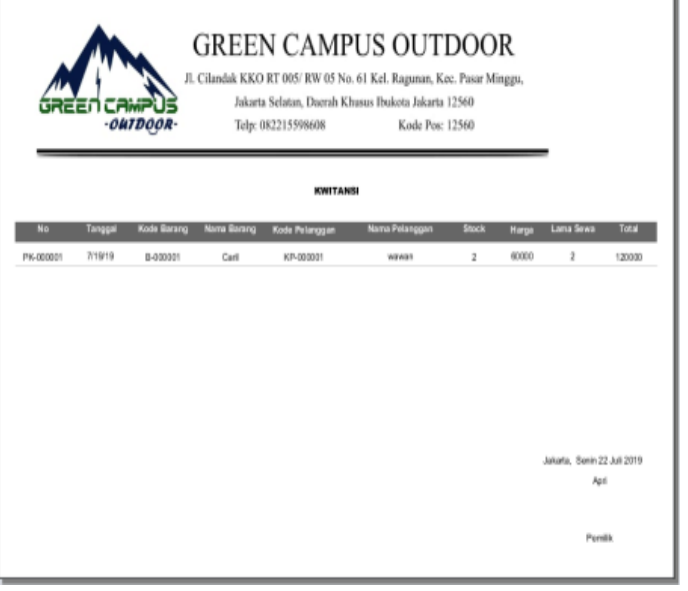

Gambar 3.20 Tampilan Kwitansi

Tampilan laporan kwitansi sebagai bukti pelanggan yang telah membeli barang. Laporan ini muncul ketika user mengklik tombol kwitansi pada form pesanan pelanggan. 
Tampilan Keluaran Data Pengembalian

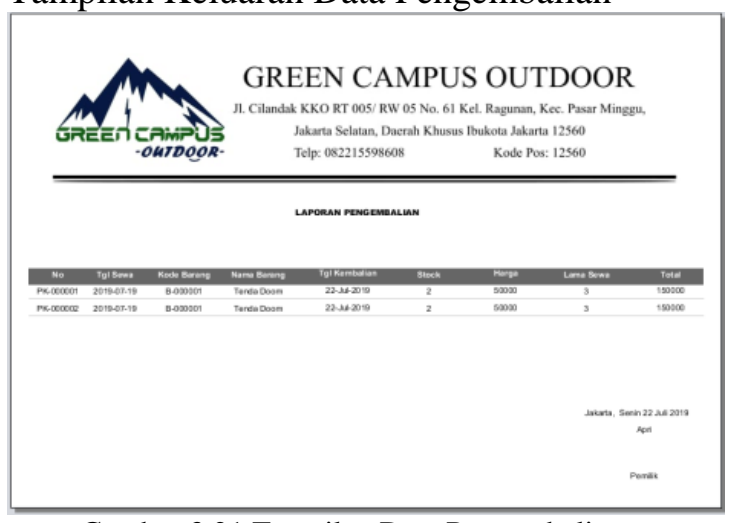

Gambar 3.21 Tampilan Data Pengembalian

Tampilan laporan data pengembalian ini berisi data-data yang ada pada tabel data pengembalian. Laporan ini muncul ketika user mengklik tombol cetak pada form laporan data pengembalian.

\section{KESIMPULAN}

Berdasarkan dari pembahasan pada bab-bab sebelumnya dan perumusan masalah yang ada, maka simpulan yang dapat diambil diantaranya :

1. Hasil implementasi sistem yang telah dibuat dirasakan lebih efektif. Penyimpanan data-data pada media database akan mempercepat dalam pencarian data. Pada proses pembuatan laporan aplikasi ini akan sangat membantu dalam pengolahan data-data yang maksimal dan efisien dalam pembuatan pengolahan penyewaan alat hiking terkait ke penyewaan pelanggan.

2. Dengan diterapkan aplikasi penyewaan alat hiking yang sudah terkomputerisasi, maka dapat mempercepat transaksi penyewaan di dalam koperasi.

3. Aplikasi yang telah dibuat dapat menunjang pembuatan laporan yang lebih efektif dan efisien.

4. Proses pencarian data yang tadinya membutuhkan waktu lama dapat teratasi dengan adanya database sehingga datadata dapat tersimpan dan diharapkan dapat mempercepat proses penyewaan.
Terima kasih kepada semua pihak yang sudah ikut serta membantu saya (penulis) dalam pembuatan dan kelancaran jurnal ini.

\section{DAFTAR PUSTAKA}

Fathansyah. (2012). Basis Data .

Hartono, B. (2013). Sistem Informasi manajemen Berbasis Komputer. Jakarta: Rineka Cipta.

Indrajani. (2011). Perancangan Basis Data dalam All in 1. Jakarta: Elex Media Komputindo.

Sukamto, R. S., \& Shalahudin, M. (2013). Rekayasa Perangkat Lunak Terstruktur dan Berorientasi Objek. Bandung: Informatika.

Tjiptjono, A. (2011). Pengaruh Kualitas Pelayanan dan Kualitass Produk Terhadap Keputusan Pembeli.

\section{UCAPAN TERIMA KASIH}

